\title{
Genotoxic and carcinogenic risks associated with the dietary consumption of repeatedly heated coconut oil
}

\author{
Smita Srivastava ${ }^{1,2}$, Madhulika Singh ${ }^{1}$, Jasmine George ${ }^{1}$, Kulpreet Bhui ${ }^{1}$, Anand Murari Saxena ${ }^{2}$ \\ and Yogeshwer Shukla ${ }^{1} *$ \\ ${ }^{1}$ Proteomics Laboratory, Indian Institute of Toxicology Research (CSIR), Mahatma Gandhi Marg, Lucknow 226 001, UP, India \\ ${ }^{2}$ Department of Zoology, Lucknow University, Lucknow 226 001, UP, India
}

(Received 9 December 2009 - Revised 19 April 2010 - Accepted 29 April 2010 - First published online 6 August 2010)

Repeated heating of vegetable oils at high temperatures during cooking is a very common cooking practice. Repeated heating of edible oils can generate a number of compounds, including polycyclic aromatic hydrocarbons (PAH), some of which have been reported to have carcinogenic potential. Consumption of these repeatedly heated oils can pose a serious health hazard. The objectives of the present study were to evaluate the genotoxic and carcinogenic risks associated with the consumption of repeatedly heated coconut oil (RCO), which is one of the commonly consumed cooking and frying medium. The PAH were analysed using HPLC in fresh CO, single-heated CO (SCO) and RCO. Results revealed the presence of certain PAH, known to possess carcinogenic potential, in RCO when compared with SCO. Oral intake of RCO in Wistar rats resulted in a significant induction of aberrant cells $(P<0.05)$ and micronuclei $(P<0.05)$ in a dose-dependent manner. Oxidative stress analysis showed a significant $(P<0.05)$ decrease in the levels of antioxidant enzymes such as superoxide dismutase and catalase with a concurrent increase in reactive oxygen species and lipid peroxidation in the liver. In addition, RCO given alone and along with diethylnitrosamine for 12 weeks induced altered hepatic foci as noticed by alteration in positive ( $\gamma$-glutamyl transpeptidase and glutathione- $S$-transferase) and negative (adenosine triphosphatase, alkaline phosphatase and glucose-6-phosphatase) hepatospecific biomarkers. A significant decrease in the relative and absolute hepatic weight of RCO-supplemented rats was recorded $(P<0.05)$. In conclusion, dietary consumption of RCO can cause a genotoxic and preneoplastic change in the liver.

Coconut oil: Polyaromatic hydrocarbons: Altered hepatic foci: Genotoxicity

Nutrition and diet as environmental factors and determinants of growth and body composition can contribute to the risk of human cancers ${ }^{(1-3)}$. Evidence pertaining to the role of dietary factors in carcinogenesis comes from both epidemiological studies and laboratory experiments. Dietary fat has been known to cause cancer of different organs ${ }^{(4)}$. Vegetable oils are a major source of fat intake, and have been used as a common medium for cooking since ages. The practice of repeated heating of edible oils is associated with adverse health effects ${ }^{(5)}$. High-temperature cooking techniques such as grilling and pan frying are associated with increased risk of carcinogenicity ${ }^{(6)}$ and genotoxicity ${ }^{(7,8)}$. Repeatedly heated fat possesses mutagenic potential ${ }^{(9)}$, and increase in mutagenicity is proportionally related to its frying time ${ }^{(10)}$. A number of genotoxic responses caused by the dietary use of heated cooking oils have also been reported ${ }^{(7,11)}$. Studies from different sources have indicated that the heating of the vegetable oils at high temperatures leads to the formation of compounds having the potential to cause cancers ${ }^{(8,12,13)}$. The heat processing of the oils at high temperatures generates food contaminants such as polycyclic aromatic hydrocarbons (PAH), a family of toxic and mild to potent carcinogenic chemicals $^{(14,15)}$. The epidemiological study done by LopezAbente et al. ${ }^{(16)}$ suggested that individuals exposed to PAH are at the risk of developing cancers. Diet is the major non-occupational source of PAH for non-smokers ${ }^{(17)}$, with meat, meat products, cereals, oils and fats being the principal sources $^{(18)}$.

Epidemiological studies have indicated that a high intake of saturated fat increases the risk of cancers ${ }^{(19)}$. Coconut oil (CO), also known as coconut butter, is a tropical oil extracted from copra (the dried inner flesh of coconuts) of Cocos nucifera (Family: Arecaceae), which is used as a cooking medium mainly in the southern parts of India and other South-East Asian countries. The CO contains predominantly medium-chain TAG, with $86.5 \%$ SFA, $5.8 \%$ MUFA and $1.8 \%$ PUFA. The SFA of CO could have an effect on atherosclerosis not only beyond their role in affecting plasma lipoproteins, but also through increased production of inflammatory cytokines in the arterial walls ${ }^{(20)}$. High-saturated fat

Abbreviations: AHF, altered hepatic foci; AlkPase, alkaline phosphatase; ATPase, adenosine triphosphatase; B $(a) \mathrm{P}$, benzo $(a)$ pyrene; CO, coconut oil; DEN, diethylnitrosamine; FCO, fresh CO; G6Pase, glucose-6-phosphatase; GGT, $\gamma$-glutamyl transpeptidase; Gr, groups; GST-P, glutathione-S-transferase placental type; LPO, lipid peroxidation; PAH, polycyclic aromatic hydrocarbons; RCO, repeatedly heated CO; ROS, reactive oxygen species; SCO, single-heated CO.

* Corresponding author: Y. Shukla, fax +91522 2628227, email yogeshwer_shukla@hotmail.com 
diet is related to oxidative stress ${ }^{(21)}$, and has a promoting effect on pancreatic carcinogenesis in azaserine-treated rats ${ }^{(22)}$.

In order to delineate the impact of repeatedly heated $\mathrm{CO}$ (RCO) use on genotoxicity and/or carcinogenicity, it is important to determine the presence of toxic chemicals which are ingested through repeatedly heated saturated fatrich diets. Thus, the present study has been designed to investigate the presence of PAH mixture in RCO using HPLC. Furthermore, the potential of RCO consumption to induce genotoxicity, oxidative stress and carcinogenicity in Wistar rats was also investigated.

\section{Materials and methods}

\section{Chemicals}

Dimethyl sulphoxide, $n$-hexane, cyclohexane, anhydrous sodium sulphate, dichloromethane, acetonitrile and silica gel were of analytical grade and purity (purchased from Merck Chemical Company, Mumbai, India). PAH standard mix was purchased from Supelco (Bellefonte, PA, USA). Diethylnitrosamine (DEN), 2-acetylaminofluorene, benzo $(a)$ pyrene $(\mathrm{B}(a) \mathrm{P}), \gamma$-glutamyl4-methoxy- $\beta$-naphthylamide, glycylglycine, fast blue BB salt (4-amino-2,5-diethoxybenzanilide diazotated zinc double salt, 4-benzoylamino-2,5-diethoxybenzenediazonion chloride (zinc chloride) salt), ATP disodium salt, sodium- $\beta$-glycerophosphate, sodium diethylbarbiturate, glucose-6-phosphate monosodium salt, $\mathrm{B}(a) \mathrm{P}$, colchicine, dichlorodihydrofluorescien-diacetate dye, phenazine methosulphate, 2-thiobarbituric acid, 1,1,3,3-tetramethoxy propane, nitroblue tetrazolium, NADPH and NADH were purchased from Sigma Chemical Company (St Louis, MO, USA). Anti-glutathione-S-transferase placental type (AntiGST-P) and goat anti-rabbit IgG peroxidase secondary antibodies were procured from Calbiochem (Darmstadt, Germany). CO (refined) used in the study was purchased from the local market (Meghdoot Oil Mills Private Limited, Mumbai, India). The rest of the chemicals that were used in the study were of analytical grade and purity, and were procured locally.

\section{Repeatedly heated coconut oil sample preparation}

The refined $\mathrm{CO}$ was heated $\left(>300^{\circ} \mathrm{C}\right)$ above its smoke point $\left(232^{\circ} \mathrm{C} ; 450^{\circ} \mathrm{F}\right)$ for $30 \mathrm{~min}$, and was cooled to room temperature. For RCO, the process was repeated six times, and the oil sample became viscous dark brown in colour after being repeatedly heated.

\section{HPLC of coconut oil}

Extraction and clean-up procedure for $\mathrm{PAH}$ was carried out using fresh $\mathrm{CO}$ (FCO), single-heated $\mathrm{CO}$ ( $\mathrm{SCO}$ ) and $\mathrm{RCO}$ according to the protocol of Pandey et al. with slight modifications. Briefly, for the extraction of PAH, $10 \mathrm{~g}$ of oil were added to $20 \mathrm{ml}$ of $n$-hexane and extracted thrice with dimethyl sulphoxide $(10 \mathrm{ml})$ followed by the addition of cold distilled water $\left(4^{\circ} \mathrm{C}\right)$ slowly, and re-extraction was done thrice with cyclohexane (solvent was changed for specific extraction of $\mathrm{PAH}$ ). After washing, it was concentrated and passed through a glass column $(20 \times 2 \cdot 2 \mathrm{~cm})$ containing silica gel and anhydrous sodium sulphate. The elution was carried out with a mixture of cyclohexane and dichloromethane, and the mixture was evaporated to dryness. The final residue was dissolved in $1 \mathrm{ml}$ of acetonitrile, and passed through a $0 \cdot 2 \mu \mathrm{m}$ filter.

Quantification of the extracted PAH was carried out using an HPLC instrument (Water Associates, Inc., Milford, MA, USA) equipped with a dual pump and Rheo dyne injector with a $20 \mu$ l loop. The reversed-phase column used for the analysis was C-18 (E. Merk, Darmstadt, Germany) with a pre-column of the same type. The column was eluted at an ambient temperature $\left(27^{\circ} \mathrm{C}\right)$ with $70: 30$ acetonitrile in water as the solvent at a flow rate of $1.5 \mathrm{ml} / \mathrm{min}$, which was monitored on an UV detector at $\lambda 254 \mathrm{~nm}$. The chromatogram was recorded and processed using Waters Millenium Software (Scientific Equipment Source, Pickering, ON, Canada). The sixteen PAH selection criteria were based on (i) the number of benzene rings in $\mathrm{PAH}$, (ii) $\mathrm{PAH}$ generally found in oils following the literature search and (iii) resolution of PAH on HPLC. The peaks of the mixture of PAH in oils were identified by comparing the retention time with that of the standard by using an UV detector for the respective fractions. Quantification of PAH was performed by comparing the integrated peak area with that of the standards ${ }^{(15)}$.

\section{Animals and treatments}

Male Wistar rats (6 weeks of age) were procured from the Indian institute of toxicology research (Lucknow, India) animal breeding colony, maintained under standard conditions and fed ad libitum a synthetic pellet basal diet (Ashirwad, Chandigharh, India) and water. Institutional guidelines for the care and use of animals were followed, and the ethical approval for the experiments was obtained from the institutional animal ethical clearance committee, Indian Institute of Technology Roorkee (IITR). All experimental procedures involving animals were approved by the animal ethical clearance committee, IITR.

\section{Chromosomal aberration and micronuclei induction assays}

Rats were randomly divided into two sets of eight groups ( $\mathrm{Gr}$ ) having six rats each. In Gr I, no treatment was given to the rats, whereas in $\mathrm{Gr}$ II, $\mathrm{B}(a) \mathrm{P}(100 \mathrm{mg} / \mathrm{kg}$ body weight; intraperitoneally) was administered to the rats $24 \mathrm{~h}$ before killing. Each rat was administered FCO $(0.5 \mathrm{ml})$ in $\mathrm{Gr}$ III, SCO in Gr IV (IVa: $0.25 \mathrm{ml}$ and IVb: $0.5 \mathrm{ml}$ ), and RCO in Gr V (Va: $0.1 \mathrm{ml}, \mathrm{Vb}: 0.25 \mathrm{ml}$ and Vc: $0.5 \mathrm{ml}$ ) consecutively by gavage. At the end of 1-week experimental period, rats were killed by cervical dislocation, and bone marrow was collected from their femurs.

\section{Oxidative stress assay}

Rats were divided equally into five Gr consisting of ten rats each, where Gr I, II and III rats were given treatments that were similar to those used for the genotoxic assays. SCO $(0.5 \mathrm{ml} / \mathrm{rat})$ and $\mathrm{RCO}(0.5 \mathrm{ml} / \mathrm{rat})$ were given by gavage to other Gr, i.e. Gr IV and V, respectively. After 1 week, rats were killed, and their livers were excised and were homogenised separately in ice-cold PBS ( $\mathrm{pH}$ 7.4) for enzymatic estimations and reactive oxygen species (ROS) determination. 


\section{Medium-term bioassay}

A total of seventy-two rats were divided into six Gr. Gr I rats were fed a normal basal diet during the entire study period, i.e.12 weeks, and they served as negative controls. Gr II, III, IV and $\mathrm{V}$ rats were given a single dose of DEN $(200 \mathrm{mg} / \mathrm{kg}$ body weight) intraperitoneally. After 1 week of recovery period, rats of Gr II were fed $0.05 \%$ 2-acetylaminofluorene in a crushed diet, and Gr III, IV and V rats were administered $0.5 \mathrm{ml} / \mathrm{rat}$ of FCO, SCO and RCO, respectively, by gavage. Simultaneously, Gr VI rats were administered RCO alone ( $0.5 \mathrm{ml} / \mathrm{rat})$. Rats were subjected to two-third partial hepatectomy after 3 weeks (Fig. 1). After killing, the livers were excised from each rat, cleaned, weighed and stored at $-80^{\circ} \mathrm{C}$ until further processing. Tissue sections $(10 \mu \mathrm{m})$ were cut from the frozen livers using a cryostat microtome (SLEE Medical GmbH, Menz, Germany), and were stained for the histochemical localisation of various markers such as GST-P, $\gamma$-glutamyl transpeptidase (GGT), glucose-6-phosphatase (G6Pase), adenosine triphosphatase (ATPase) and alkaline phosphatase (AlkPase).

\section{Methodology}

\section{Chromosomal aberration assay}

Colchicine ( $4 \mathrm{mg} / \mathrm{kg}$ of the body weight) was given to the rats $2 \mathrm{~h}$ before killing in order to arrest the metaphase stage, and a cytogenetic analysis was carried out ${ }^{(23)}$. Briefly, the bone marrow was flushed out from both the femurs using Hank's buffered salt solution ( $\mathrm{pH} 7.2$ ) and centrifuged, and the pellet was re-dispersed in a hypotonic solution $(0.56 \%, w / v)$ of $\mathrm{KCl}$ at $37^{\circ} \mathrm{C}$ to permit osmotic swelling of cells. Swollen cells were fixed in ice-cold Carnoy's fluid, placed on slides and stained with a phosphate-buffered $5 \%$ Giemsa solution. A total of

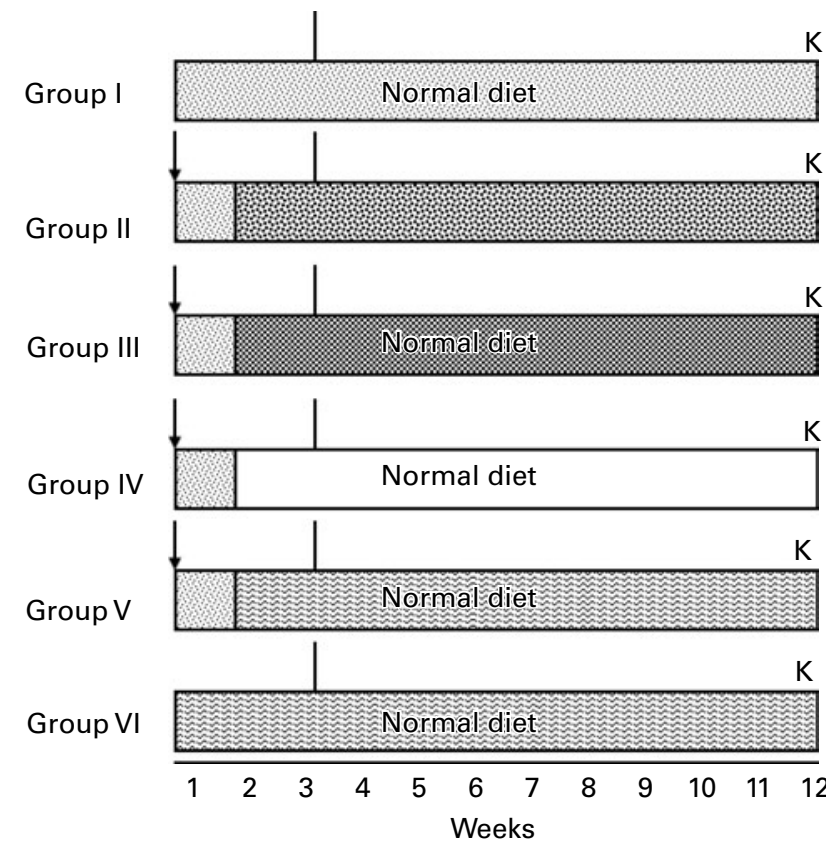

Fig. 1. Treatment schedule for medium-term bioassay. (四), Untreated; ( $\downarrow$ ),

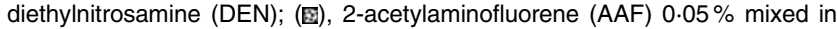
crushed diet; (圆), fresh coconut oil (FCO) $0.5 \mathrm{ml} /$ animal by gavage; ( $\square$ ), singleheated coconut oil (SCO) $0.5 \mathrm{ml} /$ animal by gavage; ( $\Xi)$, repeatedly heated coconut oil (RCO) $0.5 \mathrm{ml} /$ animal by gavage; ( I ), partial hepatectomy; K, killed. seventy-five well-spread metaphase plates per rat in each $\mathrm{Gr}$ were analysed for chromosomal aberrations at a magnification of $100 \times$, and the mitotic index was calculated from a scan of 1000 cells per rat and classified as breaks, fragments and exchanges. The incidence of aberrant cells was expressed as the percentage of damaged cells (aberrant metaphases).

\section{Micronuclei induction assay}

The frequency of micronucleated polychromatic erythrocytes was evaluated using a modified protocol of Shukla et al. ${ }^{(23)}$. The bone marrow was flushed from both the femurs using Hank's buffered salt solution, $1 \%(\mathrm{w} / \mathrm{v})$ bovine serum albumin and $0 \cdot 15 \%(\mathrm{w} / \mathrm{v})$ EDTA ( $\mathrm{pH} 7 \cdot 2)$. Evenly spread bone marrow smears were stained using the May-Grunwald and Giemsa stain. A total of 1000 polychromatic erythrocytes were scored for each treated and control Gr.

\section{Biochemical estimations of antioxidant enzymes}

The protein content of the tissue was determined by the method of Lowry et al. ${ }^{(24)}$ using bovine serum albumin as the standard. $\mathrm{Cu} / \mathrm{Zn}$ superoxide dismutase activity was analysed as per the protocol of Kakkar et al. ${ }^{(25)}$, and was expressed as specific activity (units/min per $\mathrm{mg}$ protein). The activity of catalase was analysed according to the method of Sinha ${ }^{(26)}$ using hydrogen peroxide as the substrate. The enzyme activity was measured following the disappearance of hydrogen peroxide, and expressed as $\mu \mathrm{mol}$ of hydrogen peroxide consumed/min per $\mathrm{mg}$ of protein. Lipid peroxidation (LPO) was analysed by the method of Ohkawa et $a{ }^{(27)}$, and peroxides were expressed as nmol of thiobarbituric acid-reactive substance/h per $\mathrm{mg}$ of tissue protein using 1,1,3,3-tetramethoxy propane as the standard.

\section{Reactive oxygen species generation}

ROS production was monitored by flow cytometry (BD-LSR II, San Jose, CA, USA) using dichlorodihydrofluoresciendiacetate dye ${ }^{(28)}$. The fluorescence increased due to the hydrolysis of dichlorodihydrofluorescien-diacetate to dichlorodihydrofluorescien by some non-specific cellular esterases, and its subsequent oxidation by peroxides was measured and expressed in terms of mean fluorescence intensity using the software 'CellQuest'.

\section{Medium-term bioassay}

Immunohistochemical localisation of GST-P activity was performed as per the protocol of Tatematsu et al. ${ }^{(29)}$. The exogenous peroxidase activity in fresh sections of liver was quenched with methanol: hydrogen peroxide solution in dark, and the non-specific binding was blocked using normal goat serum. The sections were incubated with the primary anti-GST-P antibody (1:300), and then with the respective secondary antibody. The colour was developed using 3-amino-9-ethylcarbazole and counterstained with haematoxylin. The histochemical activities of GGT, G6Pase, ATPase and AlkPase in rat liver were detected by the method of Shukla \& Arora ${ }^{(30)}$. Briefly, to detect GGT activity, the sections were incubated in a medium containing $\gamma$-glumatyl-4-methoxy- $\beta$-naphthlylamide 
Table 1. The amount $(\mu \mathrm{g} / \mathrm{kg})$ of polyaromatic hydrocarbons (PAH) in fresh (FCO), single-heated (SCO) and repeatedly heated coconut oil (RCO) samples

(Mean values with their standard errors of three independent set of analyses)

\begin{tabular}{|c|c|c|c|c|c|c|}
\hline \multirow[b]{3}{*}{$\mathrm{PAH}$} & \multicolumn{6}{|c|}{ Coconut oil $(\mu \mathrm{g} / \mathrm{kg})$} \\
\hline & \multicolumn{2}{|c|}{ FCO } & \multicolumn{2}{|c|}{ SCO } & \multicolumn{2}{|c|}{$\mathrm{RCO}$} \\
\hline & Mean & SE & Mean & SE & Mean & SE \\
\hline Naphthalene & $2 \cdot 98$ & $0 \cdot 10$ & 0.31 & 0.01 & 25.98 & $3 \cdot 20$ \\
\hline Acenaphthylene & 7.03 & 0.50 & $12 \cdot 2$ & 1.40 & 5.66 & 1.01 \\
\hline Fluorene + acenaphthene & 1.03 & 0.70 & 0.92 & 0.01 & 2.05 & 0.03 \\
\hline Phenanthrene & $6 \cdot 50$ & 0.40 & 9.57 & $1 \cdot 10$ & 4.87 & 0.09 \\
\hline Anthracene & 0.37 & 0.01 & $11 \cdot 23$ & 1.70 & 4.25 & $0 \cdot 10$ \\
\hline Fluoranthene & 0.78 & 0.04 & $2 \cdot 75$ & 0.08 & $12 \cdot 09$ & 2.08 \\
\hline Pyrene & 0.59 & 0.03 & 0.88 & 0.01 & $12 \cdot 38$ & 3.10 \\
\hline Benzo(a)anthracene + chrysene & 1.56 & 0.10 & $1 \cdot 2$ & 0.05 & 14.45 & 2.90 \\
\hline Benzo $(k)$ fluoranthene & 1.44 & 0.06 & 2.03 & $0 \cdot 10$ & 14.87 & 1.90 \\
\hline Benzo $(b)$ fluoranthene & 1.34 & 0.08 & $2 \cdot 32$ & 0.20 & 14.68 & $2 \cdot 20$ \\
\hline Benzo(a)pyrene & 1.33 & 0.05 & 1.68 & $0 \cdot 10$ & 18.85 & $2 \cdot 70$ \\
\hline Dibenzo $(a, h)$ anthracene & $2 \cdot 86$ & $0 \cdot 10$ & $21 \cdot 12$ & 2.80 & $15 \cdot 22$ & 1.90 \\
\hline Indeno(1,2,3cd)pyrene + Benzo $(g, h, i)$ perylene & $2 \cdot 38$ & $0 \cdot 10$ & 0.048 & 0.001 & 14.66 & $2 \cdot 10$ \\
\hline Total & $30 \cdot 19$ & & $66 \cdot 25$ & & $160 \cdot 01$ & \\
\hline
\end{tabular}

dissolved in dimethyl sulphoxide, glycylglycine and fast blue BB salt, and were transferred into a copper sulphate solution, washed and mounted. To detect G6Pase activity, sections were incubated in a medium containing lead nitrate and glucose-6-phosphate at $37^{\circ} \mathrm{C}$ for $30 \mathrm{~min}$, and were developed in yellow ammonium sulphide. The brownish black deposits of lead sulphide indicated the active site of G6Pase activity. To detect ATPase activity, the sections were incubated in a medium containing lead nitrate, magnesium chloride and ATP for $60 \mathrm{~min}$ at room temperature, and were developed in yellow ammonium sulphide. Brown precipitates indicated the site of enzyme activity. For the localisation of AlkPase activity, the sections were incubated in a freshly prepared medium containing sodium $\beta$-glycerophosphate, sodium diethylbarbiturate, calcium chloride and magnesium sulphate. After incubation, sections were transferred to cobalt nitrate solution and developed in yellow ammonium sulphide. The black deposits of cobalt sulphide indicated the site of enzyme activity.

The activity of biomarker enzymes was observed with reference to the area and count of altered hepatic foci $(\mathrm{AHF})$ in each $\mathrm{Gr}$ using Leica QWin500 image analysis software (Leica Mikrosysteme Vertrieb GmbH, Wetzlar, Germany). The image analysis was performed for each slide in triplicates with at least ten fields in each slide. The foci were scored only if their diameter was $>0 \cdot 20 \mathrm{~mm}$.
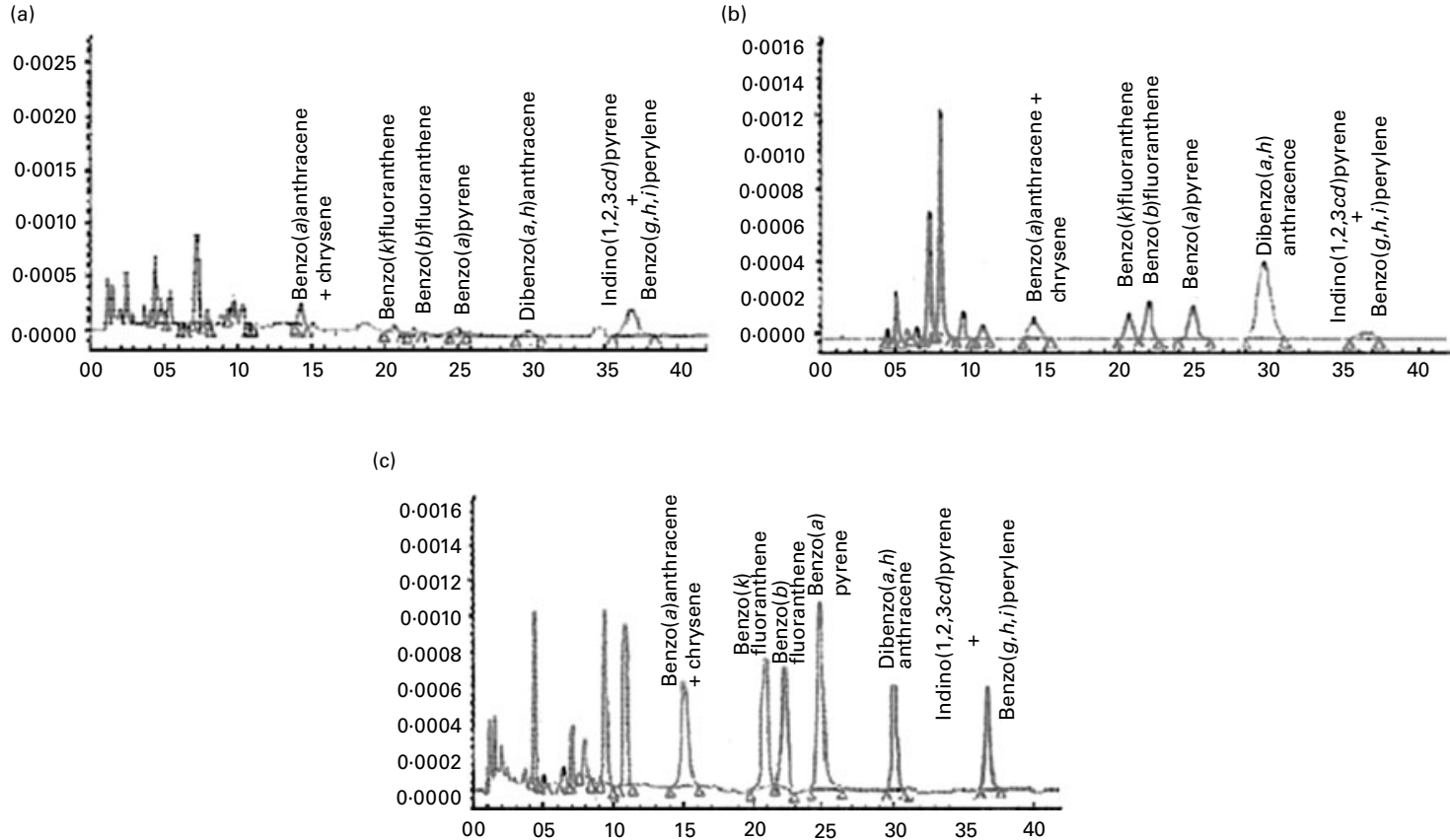

Fig. 2. HPLC chromatograms (autoscaled) showing the presence of polyaromatic hydrocarbons in coconut oil: (a) fresh coconut oil, (b) single-heated coconut oil and (c) repeatedly heated coconut oil. 
Table 2. Effects of repeatedly heated coconut oil treatment on mitotic index, chromosomal aberration and micronuclei induction in Wistar rats

(Mean values with their standard errors of ten rats)

\begin{tabular}{|c|c|c|c|c|c|c|c|c|c|c|}
\hline \multirow[b]{2}{*}{ Grt } & \multicolumn{2}{|c|}{ Mitotic index } & \multicolumn{4}{|c|}{ No. of aberrant cells (\%) } & \multicolumn{2}{|c|}{$\begin{array}{l}\text { Total no. of } \\
\text { aberrant cells }\end{array}$} & \multicolumn{2}{|c|}{$\begin{array}{c}\text { MNPCE } / 1000 \\
\text { PCE }\end{array}$} \\
\hline & Mean & SE & Breaks & Fragments & Exchanges & Multiple damages & Mean & SE & Mean & SE \\
\hline I & $5 \cdot 0$ & 0.6 & 2.42 & $2 \cdot 01$ & 0.43 & $1 \cdot 14$ & $6 \cdot 0$ & 0.4 & $4 \cdot 2$ & 0.4 \\
\hline II & 1.4 & $0 \cdot 1$ & 7.62 & 7.45 & 4.43 & $7 \cdot 70$ & $27 \cdot 2$ & 2.5 & $9 \cdot 8$ & 0.7 \\
\hline III & 4.8 & 0.3 & $2 \cdot 36$ & 2.04 & 0.21 & 1.49 & $6 \cdot 1$ & 0.7 & 4.4 & 0.4 \\
\hline $\mathrm{IVa}$ & 4.6 & 0.5 & $2 \cdot 38$ & $2 \cdot 24$ & 0.22 & 1.60 & $6 \cdot 4$ & 0.7 & 4.6 & 0.3 \\
\hline $\mathrm{IVb}$ & 4.5 & 0.5 & 2.43 & $2 \cdot 12$ & 0.25 & 2.00 & $6 \cdot 8$ & 0.9 & 4.8 & 0.8 \\
\hline Va & $3 \cdot 0^{\star \star}$ & 0.3 & 3.48 & 2.74 & 1.52 & 5.56 & $13 \cdot 3^{*}$ & $1 \cdot 2$ & $7.4^{*}$ & 0.7 \\
\hline $\mathrm{Vb}$ & $2 \cdot 2^{\star \star}$ & 0.1 & 4.62 & 3.91 & 1.55 & $5 \cdot 62$ & $15 \cdot 7^{\star}$ & $1 \cdot 3$ & $8 \cdot 5^{\star}$ & 0.5 \\
\hline Vc & $2 \cdot 1^{\star \star}$ & 0.2 & 4.87 & 4.01 & $2 \cdot 13$ & 5.49 & $16 \cdot 5^{\star}$ & 1.2 & $8.7^{*}$ & 0.9 \\
\hline
\end{tabular}

Gr, groups; MNCPE, micronucleated polychromatic erythrocytes; PCE, polychromatic erythrocyte; $B(a) P$, benzo(a)pyrene. Mean values were significantly different for induction and suppression over untreated $\mathrm{Gr} \mathrm{I}:{ }^{\star} P<0.05,{ }^{\star \star} P<0.05$.

† Gr I, untreated; Gr II, B(a)P (100 mg/kg body weight) treated; Gr III, fresh coconut oil ( $0.5 \mathrm{ml} / \mathrm{rat})$ treated; Gr IV, single-heated coconut oil (IVa: $0.25 \mathrm{ml} / \mathrm{rat}$ and IVb: $0.5 \mathrm{ml} / \mathrm{rat}$ ) treated; Gr V, repeatedly heated coconut oil (Va: $0.1 \mathrm{ml} / \mathrm{rat}, \mathrm{Vb}: 0.25 \mathrm{ml} / \mathrm{rat}$ and IVc: $0.5 \mathrm{ml} / \mathrm{rat}$ ) treated.

\section{Statistical analysis}

The statistical analysis for different parameters between different $\mathrm{Gr}$ was evaluated using Student's $t$ test; $P<0.05$ was considered significant for all the assays.

\section{Results}

Presence and amounts of polycyclic aromatic hydrocarbons in repeatedly heated coconut oil

On the basis of their molecular weight, carcinogenicity and ring sizes, PAH have been categorised into two classes: 'light PAH', such as naphthalene, acenaphthylene, fluorene + acenaphthene, phenanthrene, anthracene, fluoranthene and pyrene, and 'heavy PAH', such as benzo $(a)$ anthracene + chrysene, benzo $(k)$ fluoranthene, benzo $(b)$ fluoranthene, $\mathrm{B}(a) \mathrm{P}$, dibenzo $(a, h)$ anthracene, indeno $(1,2,3 c d)$ pyrene and benzo $(g, h, i)$ perylene ${ }^{(31)}$. Higher amount of PAH was present in RCO $(160.0 \mu \mathrm{g} / \mathrm{kg})$ than in FCO $(30.2 \mu \mathrm{g} / \mathrm{kg})$ and SCO $(66.3 \mu \mathrm{g} / \mathrm{kg}$ ) (Table 1 and Fig. 2). The amount of light PAH was $19.3 \mu \mathrm{g} / \mathrm{kg}$ (64\% of the total PAH) in FCO extract, $37.9 \mu \mathrm{g} / \mathrm{kg}$ (57\% of the total PAH) in SCO extract and $67.3 \mu \mathrm{g} / \mathrm{kg}$ ( $42 \%$ of the total PAH) in RCO extract. RCO showed an increase in the concentrations of naphthalene (9fold), fluoranthene (16-fold) and pyrene (21-fold) among the light PAH than FCO. The quantity of heavy PAH in the extracts prepared from FCO, SCO and RCO was $10.9 \mu \mathrm{g} / \mathrm{kg}$ ( $36 \%$ of the total PAH), $28.4 \mu \mathrm{g} / \mathrm{kg}$ ( $43 \%$ of the total PAH) and $92.7 \mu \mathrm{g} / \mathrm{kg}$ ( $58 \%$ of the total PAH), respectively. Apparently, out of the total content of PAH in the oil extracts, the amount of heavy PAH was more in RCO than in FCO and SCO. RCO showed an increase in the concentrations of
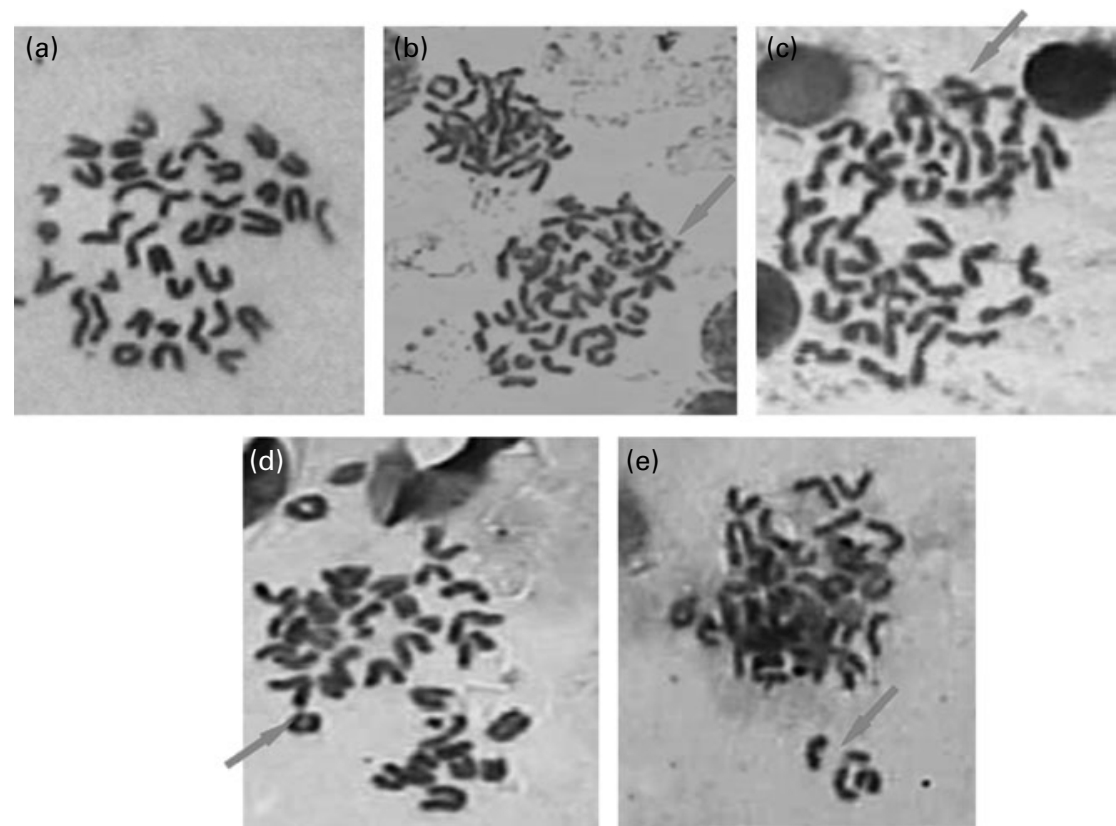

Fig. 3. Representative pictures $(100 \times)$ showing chromosomal aberrations induced by repeatedly heated coconut oil $(0.5 \mathrm{ml} / \mathrm{rat})$ in bone marrow of Wistar rats (a) no aberration; (b) exchange; (c) break; (d) ring and (e) fragment. 

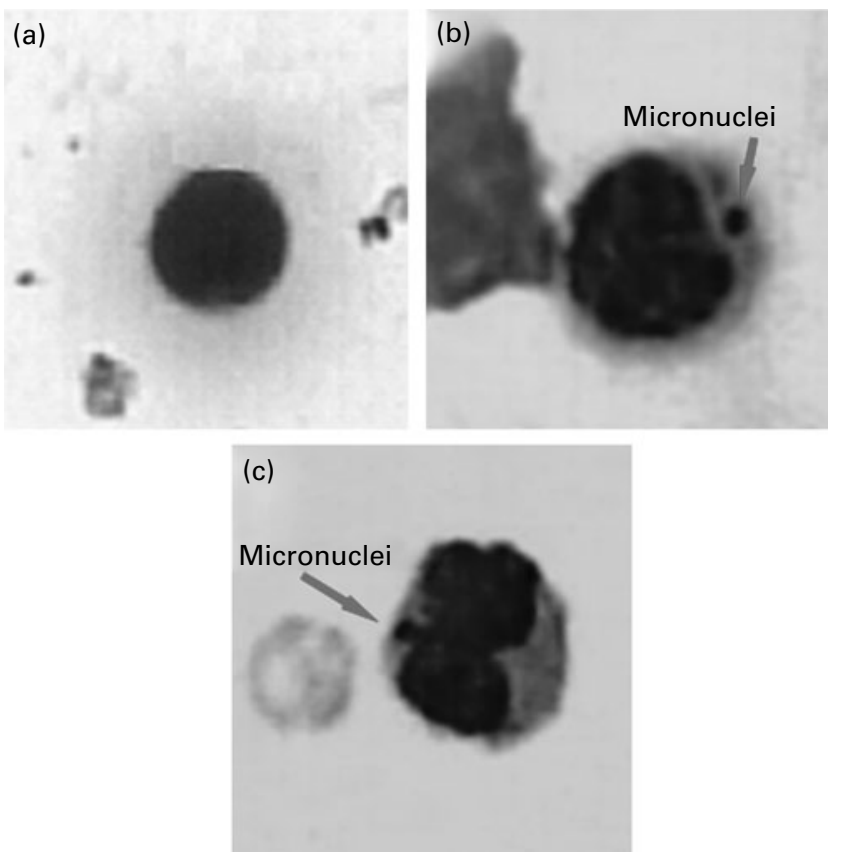

Fig. 4. Representative pictures showing micronuclei $(100 \times)$ in (a) untreated; (b) benzo(a)pyrene-treated $(100 \mathrm{mg} / \mathrm{kg}$ body weight) and (c) repeatedly heated coconut oil-treated $(0.5 \mathrm{ml} / \mathrm{rat})$ groups.

benzo $(a)$ anthracene + chrysene (9-fold), benzo $(k)$ fluoranthene (10-fold), benzo(b)fluoranthene (11-fold), B $(a) \mathrm{P}$ (14-fold), dibenzo $(a, h)$ anthracene and indeno $(1,2,3 c d)$ pyrene + benzo $(g, h, i)$ perylene (6-fold) compared with FCO (Fig. 2(c)).

Effects of repeatedly heated coconut oil repeatedly heated coconut oil on induction of micronuclei and chromosomal aberrations

Administration of RCO caused a higher incidence of micronuclei and chromosomal aberrations (Table 2 and Figs. 3 and 4 ) in rats. An induction in micronuclei of up to 2.3-fold was found in the positive control $(\mathrm{B}(a) \mathrm{P}$ administered) $\mathrm{Gr}$.
A significant induction in the percentage of aberrant cells of up to 2.2-, 2.3- and 2.4-fold was observed in the RCOadministered $\mathrm{Gr} \mathrm{Va}, \mathrm{b}$ and $\mathrm{c}$, respectively. Mitotic index was also found to decrease up to 1.6-fold in $\mathrm{Gr}$ Va, 2.3-fold in $\mathrm{Gr} \mathrm{Vb}$ and 2.4-fold in $\mathrm{Gr} \mathrm{Vc}$. A dose-dependent increase $(P<0.05)$ in the incidence of micronucleated polychromatic erythrocytes $/ 1000$ polychromatic erythrocyte was recorded in the RCO-administered rats (Table 2). SCO administration increased aberration, micronuclei induction and cytotoxicity up to a marked level compared with the FCO treatment and controls $(P<0 \cdot 05)$.

\section{Effects of repeatedly heated coconut oil on induction of oxidative stress}

A significant decrease in the levels of antioxidant enzymes catalase $(65.1 \%)$ and superoxide dismutase $(45.6 \%)$ were found in $\mathrm{B}(a) \mathrm{P}$-administered $\mathrm{Gr}$ II than in Gr I (Table 3). The activity of catalase $(55.0 \%)$ and superoxide dismutase $(28.0 \%)$ also declined in RCO-fed rats $(P<0.05)$. A considerable induction in LPO levels was observed in $\mathrm{B}(a) \mathrm{P}$ (80\%)- and RCO (40\%)-administered rats compared with the untreated controls (Table 3). However, in FCO (Gr III)- and SCO (Gr IV)-treated Gr, no significant changes in the studied parameters were observed $(P>0 \cdot 05)$.

The determination of intracellular ROS generation in terms of the mean fluorescence intensity of dichlorodihydrofluorescein-diacetate dye indicated 94.66 (SE 1.5) in the untreated $\mathrm{Gr}$, which significantly increased up to 176.68 (SE 6.6) in the $\mathrm{B}(a) \mathrm{P}$-fed $\mathrm{Gr}, 147.29$ (SE 10.2) in the RCO-fed $\mathrm{Gr}$ and 129.38 (SE 3.4) in the SCO-fed Gr.

\section{Effects of repeatedly heated coconut oil on induction of altered hepatic foci}

Rats administered DEN + 2-acetylaminofluorene ( $\mathrm{Gr}$ II) exhibited a significant $(P<0.05)$ decrease in both body weight (135.5 (SE 21.5) v. control 210.0 (SE 21.5)) and relative liver weight $(2 \cdot 84(\operatorname{SE} 0 \cdot 3) v$. control $3 \cdot 34(\operatorname{SE} 0 \cdot 4))$ compared with Gr I rats. RCO along with DEN also decreased

Table 3. Effects of repeatedly heated coconut oil treatment on levels of antioxidant enzymes and lipid peroxidation (LPO) in Wistar rats

(Mean values with their standard errors of ten rats)

\begin{tabular}{|c|c|c|c|c|c|c|}
\hline \multirow[b]{2}{*}{ Grł } & \multicolumn{2}{|c|}{$\begin{array}{l}\text { Cu/Zn superoxide } \\
\text { dismutase (unit/min } \\
\text { per mg protein) } \dagger\end{array}$} & \multicolumn{2}{|c|}{$\begin{array}{c}\text { Catalase }(\mu \mathrm{m} / \mathrm{min} \text { per } \mathrm{mg} \\
\text { protein) } \dagger\end{array}$} & \multicolumn{2}{|c|}{$\begin{array}{l}\text { LPO (nm TBARS/mg } \\
\text { protein) } \dagger\end{array}$} \\
\hline & Mean & SE & Mean & SE & Mean & SE \\
\hline 1 & 0.068 & 0.003 & $195 \cdot 12$ & 11.7 & 3.20 & 0.2 \\
\hline II & $0.037^{\star}(45 \cdot 6 \%)$ & 0.001 & $68 \cdot 06^{*}(65 \cdot 1 \%)$ & 4.7 & $5 \cdot 76^{\star \star}(80 \cdot 0 \%)$ & $0 \cdot 3$ \\
\hline III & $0.063(7.3 \%)$ & 0.002 & $178.30(8.6 \%)$ & 12.5 & $3.36(5.14 \%)$ & 0.2 \\
\hline IV & $0.062(9.4 \%)$ & 0.003 & $174.64(10.5 \%)$ & $12 \cdot 2$ & $3.59(12.2 \%)$ & 0.3 \\
\hline V & $0.049^{*}(27.94 \%)$ & 0.002 & $87.85^{\star}(54.98 \%)$ & 5.7 & $4.47^{\star \star}(39.68 \%)$ & 0.3 \\
\hline
\end{tabular}

Gr, groups; TBARS, thiobarbituric acid-reactive substance.

Mean values significantly decrease in the level of antioxidant enzymes over untreated $\mathrm{Gr} I$ and significantly increase in LPO of rats over untreated Gr I: ${ }^{\star} P<0.05,{ }^{\star \star} P<0.05$.

$\dagger$ Numbers given in the parentheses indicate the percentage change over untreated $\mathrm{Gr}$ I.

‡ Gr I, untreated; Gr II, B(a)P (100 mg/kg body weight) treated; Gr III, fresh coconut oil $(0.5 \mathrm{ml} / \mathrm{rat})$ treated; Gr IV single-heated coconut oil $(0.5 \mathrm{ml} / \mathrm{rat})$ treated; Gr V, repeatedly heated coconut oil $(0.5 \mathrm{ml} / \mathrm{rat})$ treated. 
Table 4. Altered hepatic foci-inducing effects of repeatedly heated coconut oil treatment in Wistar rats in terms of the percentage area (foci/mm²) (Mean values with their standard errors of ten rats)

\begin{tabular}{|c|c|c|c|c|c|c|c|c|c|c|c|}
\hline \multirow[b]{2}{*}{ Gr } & \multirow[b]{2}{*}{ Treatment } & \multicolumn{2}{|c|}{ Alkaline phosphatase $\dagger$} & \multicolumn{2}{|c|}{ ATP† } & \multicolumn{2}{|c|}{ Glucose-6-phosphatase $\dagger$} & \multicolumn{2}{|c|}{ Glutathione-S-transferase $\dagger$} & \multicolumn{2}{|c|}{$\gamma$-Glutamyl transpeptidase $\dagger$} \\
\hline & & Mean & SE & Mean & SE & Mean & SE & Mean & SE & Mean & SE \\
\hline I & Untreated & 2.04 & 0.05 & 1.92 & 0.02 & 2.44 & 0.05 & 1.90 & 0.04 & 2.58 & 0.30 \\
\hline II & $\mathrm{DEN}+2-\mathrm{AAF}$ & $0.43(79.0 \%) \downarrow \S$ & 0.01 & $0.29(85 \%) \downarrow \S$ & 0.06 & $0.18(93 \%) \downarrow \S$ & 0.03 & $4.11(116.0 \%) \uparrow^{*}$ & 0.80 & $5.30(105.0 \%) \uparrow^{*}$ & 0.60 \\
\hline III & $\mathrm{DEN}+\mathrm{FCO}$ & $2.01(1.5 \%)$ & 0.21 & $1.85(3.6 \%)$ & 0.10 & $2.41(1.2 \%)$ & 0.01 & $2.08(9.4 \%)$ & 0.10 & $2.70(4.6 \%)$ & 0.30 \\
\hline IV & $\mathrm{DEN}+\mathrm{SCO}$ & $1.92(5.9 \%)$ & 0.15 & $1.76(8.3 \%)$ & 0.06 & $2.26(7.4 \%)$ & 0.01 & $2.11(11.2 \%)$ & 0.50 & $2.82(9.3 \%)$ & 0.20 \\
\hline v & $\mathrm{DEN}+\mathrm{RCO}$ & $0.87(57.0 \%) \downarrow \S$ & 0.09 & $1.00(48 \%) \downarrow \S$ & 0.11 & $1.32(46 \%) \downarrow \S$ & 0.14 & $3.27(71.0 \%) \uparrow *$ & 0.34 & $3.92(52.0 \%) \uparrow$ * & 0.40 \\
\hline VI & Saline + RCO & $1.44(29.4 \%) \downarrow \S$ & 0.20 & $1.38(28 \%) \downarrow \S$ & 0.18 & $1.72(29.5 \%) \downarrow \S$ & 0.26 & $2.44(28.4 \%) \uparrow^{*}$ & 0.21 & $3.28(27.0 \%) \uparrow$ * & 0.30 \\
\hline
\end{tabular}

Gr, groups; DEN, diethylnitrosamine; 2-AAF, 2-acetylaminofluorene; FCO, fresh coconut oil, SCO, single-heated coconut oil; RCO, repeatedly heated coconut oil.

${ }^{*}$ Mean values were significantly different in induction $(\uparrow)$ in the level of positive biomarkers with respect to $\operatorname{Gr} I(P<0.05)$.

$\dagger$ Numbers given in the parentheses indicate the percentage change over to $\mathrm{Gr} l$.

F Gr I, untreated; Gr II, DEN (200 mg/kg body weight) + 2-AAF (0.05\% in crushed diet) treated; Gr III, DEN (200 mg/kg body weight) + FCO (0.5 ml/rat) treated; Gr IV, DEN (200 mg/kg body weight) + SCO (0.5 ml/rat) treated; Gr V, DEN (200 mg/kg body weight) + RCO (0.5 ml/rat) treated; Gr Vl, RCO $(0.5 \mathrm{ml} /$ rat) treated.

$\S$ The symbol $\downarrow$ represents significant suppression in the level of negative biomarkers.

Table 5. Altered hepatic foci-inducing effects of repeatedly heated coconut oil treatment in Wistar rats in terms of the count of foci/ $/ \mathrm{mm}^{2}$

(Mean values with their standard errors of ten rats)

\begin{tabular}{|c|c|c|c|c|c|c|c|c|c|c|c|}
\hline \multirow[b]{2}{*}{ Grł } & \multirow[b]{2}{*}{ Treatment } & \multicolumn{2}{|c|}{ Alkaline phosphatase $\dagger$} & \multicolumn{2}{|l|}{ ATP† } & \multicolumn{2}{|c|}{ Glucose-6-phosphatase $†$} & \multicolumn{2}{|c|}{ Glutathione-S-transferase $\dagger$} & \multicolumn{2}{|c|}{$\begin{array}{l}\gamma \text {-Glutamyl transpepti- } \\
\text { dase† }\end{array}$} \\
\hline & & Mean & $\mathrm{SE}$ & Mean & SE & Mean & SE & Mean & SE & Mean & SE \\
\hline 1 & Untreated & 48.4 & $5 \cdot 2$ & 924.5 & 94.5 & $286 \cdot 3$ & 29.5 & $348 \cdot 2$ & 35.8 & 252.5 & $25 \cdot 3$ \\
\hline II & $\mathrm{DEN}+2-\mathrm{AAF}$ & $7.8(84.0 \%) \S$ & 0.9 & $220.6(76.0 \%) \S$ & $23 \cdot 3$ & $86.6(70.0 \%) \S$ & 9.5 & $636.4(83.0 \%)^{\star}$ & $62 \cdot 2$ & $479.3(89.0 \%)^{*}$ & $50 \cdot 3$ \\
\hline III & $\mathrm{DEN}+\mathrm{FCO}$ & $44.6(7.8 \%)$ & $5 \cdot 2$ & 892.6 (3.4\%) & $10 \cdot 2$ & $263.4(7.9 \%)$ & $26 \cdot 5$ & $364.8(4.8 \%)$ & 36.5 & $270.3(7.0 \%)$ & 28.4 \\
\hline IV & $\mathrm{DEN}+\mathrm{SCO}$ & $42.6(12.0 \%)$ & 4.8 & $841.3(9.0 \%)$ & 83.7 & $260.5(9.0 \%)$ & 18.4 & $384.8(10.5 \%)$ & $36 \cdot 8$ & $280(11.0 \%)$ & $26 \cdot 7$ \\
\hline V & DEN + RCO & $28.4(41.0 \%) \S$ & 30.5 & $570.7(38.0 \%) \S$ & $56 \cdot 8$ & $182.8(36.0 \%) \S$ & 19.5 & $498.2(43.0 \%)^{\star}$ & $20 \cdot 3$ & $386.3(53.0 \%)^{\star}$ & $12 \cdot 8$ \\
\hline $\mathrm{VI}$ & Saline + RCO & $33.3(31.0 \%) \S$ & 5.5 & $718.5(22.0 \%) \S$ & $90 \cdot 3$ & $225.6(21.0 \%) \S$ & $29 \cdot 1$ & $439.5(26.0 \%)^{\star}$ & $36 \cdot 6$ & $326.6(29.0 \%)^{*}$ & $28 \cdot 2$ \\
\hline
\end{tabular}

Gr, groups; DEN, diethylnitrosamine; 2-AAF, 2-acetylaminofluorene; FCO, fresh coconut oil; SCO, single-heated coconut oil; RCO, repeatedly heated coconut oil.

* Mean values were significantly different in induction in the level of positive biomarkers with respect to $\mathrm{Gr} I(P<0.05)$.

₹ Gr I, untreated; Gr II, DEN (200 mg/kg body weight) + 2-AAF (0.05\% in crushed diet) treated; Gr III, DEN (200 mg/kg body weight) + FCO (0.5 ml/rat) treated; Gr IV, DEN (200 mg/kg body weight) + SCO (0.5 ml/rat) treated;

$\S$ Significant suppression in the level of negative biomarkers are represented. 
relative liver weight (3.00 (SE 0.4); $P<0.05)$, whereas no change in body weight was observed. FCO and SCO treatments had no effects on the body weight and liver weight of rats when compared with the treatment given to Gr I rats $(P>0.05)$.

The results revealed significant changes in positive (increase in GST-P and GGT) and negative biomarker (decrease in AlkPase, ATPase and G6Pase) levels in $\mathrm{Gr}$ given $\mathrm{DEN}+2$-acetylaminofluorene (Gr II), $\mathrm{DEN}+\mathrm{RCO}$ $(\mathrm{Gr} \mathrm{V})$ and RCO alone (Gr VI) with respect to the untreated Gr, Gr I (Tables 4 and 5 and Fig. 5; $P<0 \cdot 05$ ). No alterations were observed in any positive or negative biomarkers by oral administration of either FCO (Gr III) or SCO (Gr IV) compared with the untreated controls $(P>0.05)$.

\section{Discussion}

Food that we eat may contain carcinogenic contaminants, or may become a mutagen itself after the transformation of some of its components ${ }^{(32)}$. To date, many dietary constituents have been studied for their carcinogenic or mutagenic potential $^{(3,11,33)}$. Relationship between dietary use of vegetable fats and risk of cancers has long been known, but studies exploring the mechanism for this connection are ambiguous. In this context, the present study was conducted to identify and quantify the contaminants generated in $\mathrm{CO}$ during the process of repeated heating to the temperatures usually used for cooking. There are reports regarding the formation of carcinogenic compounds by the heat processing of vegetable oils ${ }^{(11,12)}$. These compounds may form DNA adducts, which have been proposed as predictive biomarkers of human cancers $^{(34)}$. Results of the study revealed the presence of a higher amount of total PAH in RCO (six times heated) than in SCO and FCO (Table 1). Pandey et al. ${ }^{(15)}$ also reported that repeated heating of edible oil at high temperatures generates greater amounts of $\mathrm{PAH}$, which are dependent on the number of cycles used for heating. Moreover, RCO contained a higher amount of heavy PAH of the total PAH than FCO and SCO. Heavy PAH are reported to have significant carcinogenic and mutagenic potential ${ }^{(35)}$.

As the amount of PAH was high in RCO, it is assumed that its dietary use may result in risk of genotoxicity and carcinogenicity. The assays performed to detect both chromosomal aberration and micronuclei induction in the bone morrow are considered to be able to detect early effects of genotoxicity following the exposure to mutagens and carcinogens ${ }^{(23)}$. By using these two assays in the present study, RCO was found to enhance the incidence of aberrant cells, including breaks, fragments, exchanges and multiple chromosomal damages and micronuclei in a dose-dependent manner (Table 2). Chromosomal aberration and micronuclei induction by $\mathrm{B}(a) \mathrm{P}^{(23)}$ and heated cooking oils ${ }^{(36)}$ are well documented. The results of the present study suggest that RCO may contain a high amount of $\mathrm{B}(a) \mathrm{P}$ (Table 1).
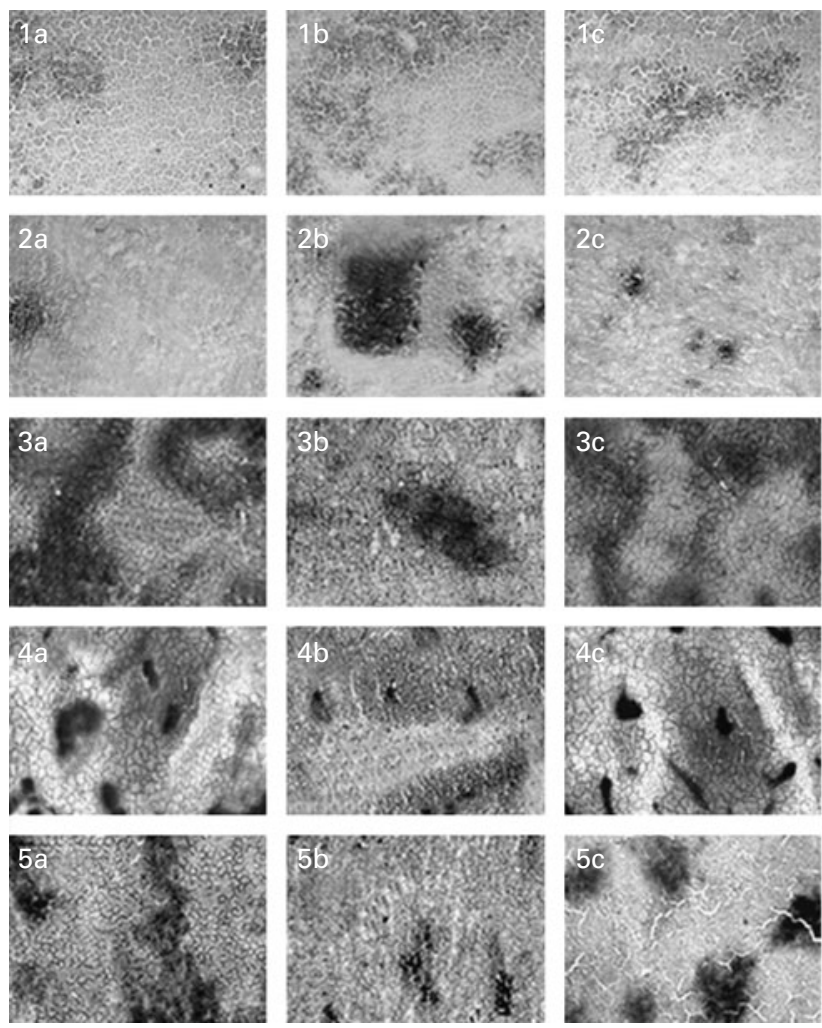
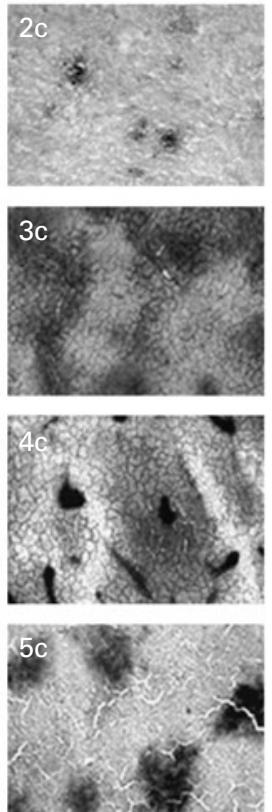
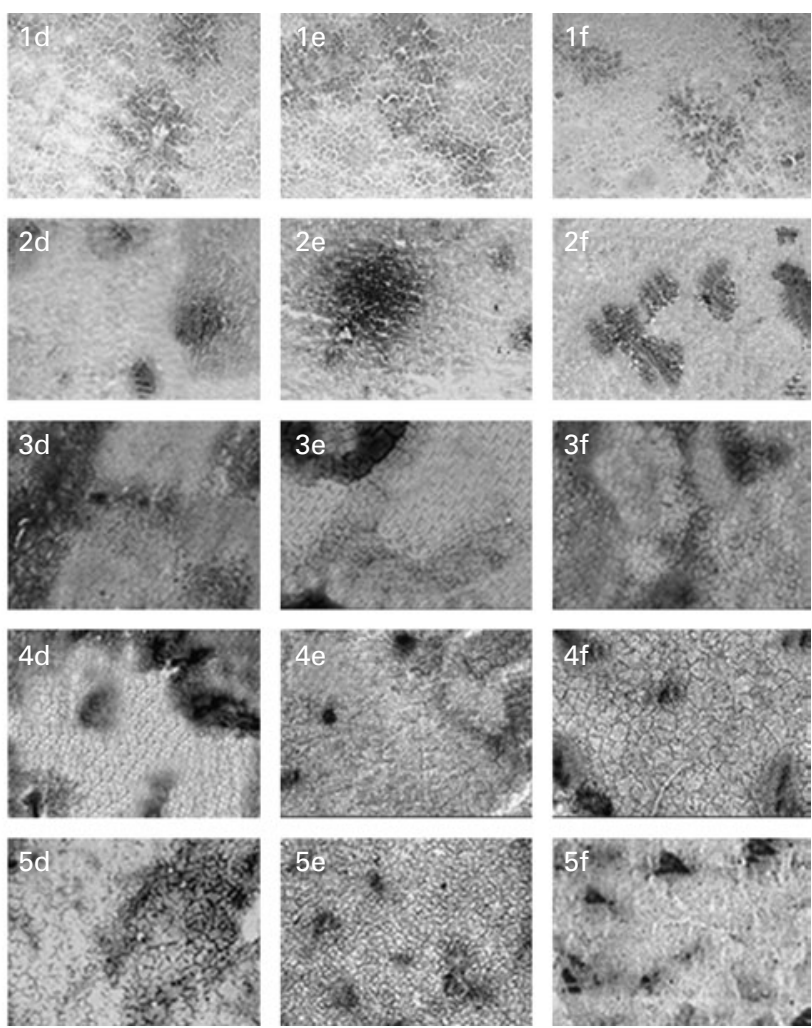

Fig. 5. Representative pictures $(10 \times)$ for cellular localisation of the expression of liver-specific enzyme markers showing (1) $\gamma$-glutamyl transpeptidase, $(2)$ glutathione-S-transferase, (3) ATP, (4) glucose-6-phosphatase, (5) alkaline phosphatase, where (1a-5a) represent untreated group; (1b-5b) represent diethylnitrosamine $(200 \mathrm{mg} / \mathrm{kg}$ body weight) +2 -acetylaminofluorene $(0.05 \%$ in crushed diet)-treated group; (1c-5c) represent diethylnitrosamine (200 mg/kg body weight $)+$ fresh coconut oil $(0.5 \mathrm{ml} / \mathrm{rat})$-treated group; $(1 \mathrm{~d}-5 \mathrm{~d})$ represent diethylnitrosamine $(200 \mathrm{mg} / \mathrm{kg}$ body weight $)+$ single-heated coconut oil $(0.5 \mathrm{ml} / \mathrm{rat})$ treated group; $(1 \mathrm{e}-5 \mathrm{e})$ represent diethylnitrosamine $(200 \mathrm{mg} / \mathrm{kg}$ body weight) + repeatedly heated coconut oil (RCO; $0.5 \mathrm{ml} / \mathrm{rat})$-treated group; (1f-5f) represent RCO $(0.5 \mathrm{ml} / \mathrm{rat})$-treated group. 
The prevention of oxidation is an essential process as decreased antioxidant levels may lead to cytotoxicity, mutagenicity and carcinogenicity ${ }^{(37,38)}$. There is evidence linking the metabolism of PAH with the generation of ROS and thus oxidative stress ${ }^{(39)}$. Cooking oil fumes were found to induce DNA damage via ROS production ${ }^{(8)}$. Our results revealed a significant $(P<0 \cdot 05)$ decrease in the levels of antioxidant enzymes (viz. catalase and superoxide dismutase) and increase in the levels of LPO and ROS following RCO administration (Table 3). Accordingly, the decrease in the levels of antioxidant enzymes has been observed earlier in rats fed heated and fried oil ${ }^{(40)}$. Altered levels of antioxidant enzymes are evident in cancers ${ }^{(38)}$. From the present set of observations, it has been concluded that RCO has the potential to cause oxidative imbalance by decreasing antioxidant enzyme levels and increasing ROS and LPO, which in turn may cause susceptibility towards cancer development ${ }^{(8)}$. Ip \& Sinha ${ }^{(41)}$ reported that saturated fat induces LPO. A study done by Udilova et al. ${ }^{(42)}$ suggested that the peroxidation of biomembranes by hydroperoxides from heated oils may contribute to enhanced risk of cancers. In another study, $1, N(6)$-ethenodeoxyadenosine, which is determined as a marker for DNA damage caused by LPO products and a marker for oxidative stress, formed the highest adducts in the $\mathrm{CO}$ diet ${ }^{(43)}$.

Induction of preneoplastic lesions is among the events leading to liver tumour development, and has been used to assess the carcinogenic/anticarcinogenic potential of various agents $^{(30)}$. A number of genotoxic responses have been reported in fresh or heat-treated foodstuffs, which are also reported to be carcinogenic in rodent bioassays. Earlier, we have shown that heated mustard oil induces AHF significantly ${ }^{(30)}$. In the present study, investigations were performed for the evaluation of AHF-developing potential of RCO. A significant enhancement in the expression of positive biomarker enzymes (GGT and GST-P) and a reduction in negative markers (AlkPase, ATPase and G6Pase) were observed in the rats administered DEN + RCO and RCO alone compared with the FCO- and SCO-treated Gr (Tables 4 and 5). GST-P is used as a diagnostic marker for hepatocellular carcinoma, and is also used for the detection of other chronic liver diseases ${ }^{(44)}$. Another study suggested that a deficiency in canalicular ATPase and G6Pase provides the best marker for the larger foci and nodules, and thus can be used to identify preneoplastic changes in the liver ${ }^{(45)}$. Aruna et al. ${ }^{(46)}$ suggested that initiation of hepatocarcinogenesis is influenced by thermally oxidised vegetable oil. The AHF-inducing activity of RCO in DEN-initiated rats may be attributed to its SFA. Repeatedly used frying oils when administered to rats have been shown to produce indications of cellular damage to the liver and kidneys ${ }^{(47)}$. RCO leads to the induction of oxidative stress, which in turn inhibits the activity of enzymes such as G6Pase and ATPase within the cells ${ }^{(13)}$. Increase in ROS production is related to epigenetic toxicity ${ }^{(48)}$, and also accounts for GST-P induction in hepatocytes ${ }^{(49)}$. Since tumour initiation and promotion involve genetic and epigenetic pathways, respectively, it seems like RCO (Table 1) having more amounts of carcinogenic PAH and inducing AHF alone as well as with DEN works both as an initiator and as a promoter.

In conclusion, the presence of a high amount of carcinogenic PAH in RCO was responsible for oxidative stress via enhancement of ROS generation and LPO, thus leading to the formation of preneoplastic lesions in rat liver. Therefore, dietary consumption of RCO exhibits the possible risk of carcinogenicity and genotoxicity.

\section{Acknowledgements}

The authors thank all their colleagues who were involved in the study for their excellent assistance. All authors participated in the development of the study concept and design; S. S. and M. S. were responsible for the execution of the study; K. B. was responsible for the flow cytometry work; S. S. and A. M. S. were responsible for the chemical analysis of oil samples; J. G. and Y. S. were responsible for the Image analysis; all authors were involved in the data interpretation; S. S. wrote the draft of the manuscript; M. S., A. M. S., J. G., K. B. and Y. S. reviewed and revised the manuscript. The authors thank the Director, Indian Institute of Toxicology Research, Lucknow, for his keen interest in the study. They are also thankful to the analytical toxicology section of IITR for their technical support and assistance with HPLC analysis. The authors are thankful to CSIR, New Delhi, for funding this work from Task force project NWP-17. No conflicts of interest are declared by the authors.

\section{References}

1. Granados S, Quiles JL, Gil A, et al. (2006) Dietary lipids and cancer. Nutr Hosp 2, 42-52, 44-54.

2. Ichinose T, Nobuyuki S, Takano H, et al. (2004) Liver carcinogenesis and formation of 8-hydroxy-deoxyguanosine in $\mathrm{C} 3 \mathrm{H} /$ $\mathrm{HeN}$ mice by oxidized dietary oils containing carcinogenic dicarbonyl compounds. Food Chem Toxicol 42, 1795-1803.

3. Taghavi N \& Yazdi I (2007) Type of food and risk of oral cancer. Arch Iran Med 10, 227-232.

4. Woutersen RA, Appel MJ, van Garderen-Hoetmer A, et al. (1999) Dietary fat and carcinogenesis. Mutat Res 443, 111-127.

5. Ima-Nirwana S, Ahmad SN, Yee LJ, et al. (2007) Reheating of soy oil is detrimental to bone metabolism in oestrogen deficient rats. Singapore Med J 48, 200-206.

6. Sinha R, Chow WH, Kulldorff M, et al. (1999) Well-done, grilled red meat increases the risk of colorectal adenomas. Cancer Res 59, 4320-4324.

7. Li S, Wang Y, Zhang J, et al. (1999) Study on the chemical components of edible oil fume in kitchen and its genotoxity on Drosophila. Wei Sheng Yan Jiu 28, 15-17.

8. Dung CH, Wu SC \& Yen GC (2006) Genotoxicity and oxidative stress of the mutagenic compounds formed in fumes of heated soybean oil, sunflower oil and lard. Toxicol In Vitro 20, 439-447.

9. Hageman G, Kikken R, Ten Hoor F, et al. (1988) Assessment of mutagenic activity of repeatedly used deep-frying fats. Mutat Res 204, 593-604.

10. Chen YC, Chiu CP \& Chen BH (2003) Mutagenicity of fumes from fried chicken legs. J Food Prot 66, 1269-1276.

11. Chiang TA, Pei-Fen W, Ying LS, et al. (1999) Mutagenicity and aromatic amine content of fumes from heated cooking oils produced in Taiwan. Food Chem Toxicol 37, 125-134.

12. Wu PF, Chiang TA, Wang LF, et al. (1998) Nitro-polycyclic aromatic hydrocarbon contents of fumes from heated cooking oils and prevention of mutagenicity by catechin. Mutat Res 403, 29-34.

13. Wu SC \& Yen GC (2004) Effects of cooking oil fumes on the genotoxicity and oxidative stress in human lung carcinoma (A-549) cells. Toxicol In Vitro 18, 571-580. 
14. Ramesh SA, Walker DB, Hood MD, et al. (2004) Bioavailability and risk assessment of orally ingested polycyclic aromatic hydrocarbons. Int J Toxicol 23, 301-333.

15. Pandey MK, Dhawan A \& Das M (2006) Induction of p53, p21waf1, orinithine decorboxylase activity, and DNA damage leading to cell-cycle arrest and apoptosis following topical application of repeated fish fried oil extract to mice. Mol Carcinog 45, 805-813.

16. Lopez-Abente G, Sanz-Anquela JM \& Gonzalez CA (2001) Consumption of wine stored in leather wine bottles and incidence of gastric cancer. Arch Environ Health 56, 559-561.

17. Lodovici M, Dolara P, Casalini C, et al. (1995) Polycyclic aromatic hydrocarbon contamination in the Italian diet. Food Addit Contam 12, 703-713.

18. Ibáñez R, Agudo A, Berenguer A, et al. (2005) Dietary intake of polycyclic aromatic hydrocarbons in a Spanish population. J Food Prot 68, 2190-2195.

19. Caygill CP, Charlett A \& Hill MJ (1996) Fat, fish, fish oil and cancer. Br J Cancer 74, 159-164.

20. Alexaki A, Wilson TA, Atallah MT, et al. (2004) Hamsters fed diets high in saturated fat have increased cholesterol accumulation and cytokine production in the aortic arch compared with cholesterol-fed hamsters with moderately elevated plasma non-HDL cholesterol concentrations. J Nutr 134, 410-415.

21. Augusti KT, Chackery J, Jacob J, et al. (2005) Beneficial effects of a polar fraction of garlic (Allium sativum Linn) oil in rats fed with two different high fat diets. Indian J Exp Biol 43, 76-83.

22. Appel MJ, nan Garderen-Hoetmer A \& Woutersen RA (1990) Azaserine-induced pancreatic carcinogenesis in rats: promotion by a diet rich in saturated fat and inhibition by a standard laboratory chow. Cancer Lett 55, 239-248.

23. Shukla Y, Arora A \& Taneja P (2003) Antigenotoxic potential of certain dietary constituents. Teratog Carcinog Mutagen 1, $323-335$

24. Lowry OH, Rosebrough NJ, Farr AL, et al. (1951) Protein measurement with the Folin phenol reagent. J Biol Chem 193, 265-275.

25. Kakkar P, Das B \& Viswanathan PN (1984) A modified spectrophotometric assay of superoxide dismutase. Indian J Biochem Biophys 21, 130-132.

26. Sinha AK (1972) Colorimetric assay of catalase. Anal Biochem 47, 389-394.

27. Ohkawa H, Ohisi N \& Yagi K (1979) Assay for lipid peroxides in animal tissues by thiobarbutric acid reaction. Anal Biochem 95, 351-358.

28. Esposti DM \& McLennan H (1998) Mitochondria and cells produce reactive oxygen species in virtual anaerobiosis: relevance to ceramide-induced apaotosis. Febs Lett 430, 338-342.

29. Tatematsu M, Mera Y, Inoue T, et al. (1988) Stable phenotypic expression of glutathione- $S$-transferase placental type and unstable phenotypic expression of $\gamma$-glutamyl transferase in rat liver preneoplastic and neoplastic lesions. Carcinogenesis 9, 215-220.

30. Shukla Y \& Arora A (2003) Enhancing effects of mustard oil on preneoplastic hepatic foci development in Wistar rats. Hum Exp Toxicol 22, 51-55.

31. Moret S, Purcaro G \& Conte LS (2007) Polycyclic aromatic hydrocarbon $(\mathrm{PAH})$ content of soil and olives collected in areas contaminated with creosote released from old railway ties. Sci Total Environ 386, 1-8.
32. Uauy R \& Solomons N (2005) Diet, nutrition, and the life-course approach to cancer prevention. J Nutr 135, 2934S-2945S.

33. Sauer LA, Blask DE \& Dauchy RT (2007) Dietary factors and growth and metabolism in experimental tumors. $J$ Nutr Biochem 18, 637-649.

34. Schaffer EM \& Milner JA (1996) Impact of dietary fatty acids on 7,12-dimethylbenz $[a]$ anthracene-induced mammary DNA adducts. Cancer Lett 106, 177-183.

35. Marsili L, Caruso A, Fossi MC, et al. (2001) Polycyclic aromatic hydrocarbons (PAHs) in subcutaneous biopsies of Mediterranean cetaceans. Chemosphere 44, 147-154.

36. Isidori M \& Parrella A (2009) Genotoxicity of aqueous extract from heated cooking oils and its suppression by lactobacilli. Food Sci Technol Int (Epublication ahead of print version 1 June 2009).

37. Mates JM (2000) Effects of antioxidant enzymes in the molecular control of reactive oxygen species toxicology. Toxicology 153, 83-104.

38. Narchonai E, Shila S \& Panneerselvam C (2006) Enzymatic and non-enzymatic antioxidant status in stage (III) human oral squamous cell carcinoma and treated with radical radio therapy: influence of selenium supplementation. Clin Chim Acta 373, 92-98.

39. Camus L, Birkely SR, Jones MB, et al. (2003) Biomarker responses and PAH uptake in Mya truncata following exposure to oil-contaminated sediment in an Arctic fjord (Svalbard). Sci Total Environ 308, 221-234.

40. Narasimhamurthy K \& Raina PL (1999) Long-term feeding effect of thermally oxidised oils on antioxidant enzymes in rats. Indian J Exp Biol 37, 1042-1045.

41. Ip C \& Sinha D (1981) Anticarcinogenic effect of selenium in rats treated with dimethylbenz $[a]$ anthracene and fed different levels and types of fat. Carcinogenesis 2, 435-438.

42. Udilova N, Jurek D, Marian B, et al. (2003) Induction of lipid peroxidation in biomembranes by dietary oil components. Food Chem Toxicol 41, 1481-1489.

43. Eder E, Wacker M, Lutz U, et al. (2006) Oxidative stress related DNA adducts in the liver of female rats fed with sunflower-, rapeseed-, olive- or coconut oil supplemented diets. Chem Biol Interact 159, 81-89.

44. Yusof YA, Yan KL \& Hussain SN (2003) Immunohistochemical expression of pi class glutathione- $S$-transferase and alpha-fetoprotein in hepatocellular carcinoma and chronic liver disease. Anal Quant Cytol Histol 25, 332-338.

45. Glauert HP, Beer D, Rao MS, et al. (1986) Induction of altered hepatic foci in rats by the administration of hypolipidemic peroxisome proliferators alone or following a single dose of diethylnitrosamine. Cancer Res 46, 4601-4606.

46. Aruna K, Rukkumani R, Varma SP, et al. (2005) Therapeutic role of Cuminum cyminum on ethanol and thermally oxidized sunflower oil induced toxicity. Phytother Res 19, 416-442.

47. Hageman G, Verhagen H, Schutte B, et al. (1991) Biological effects of short-term feeding to rats of repeatedly used deepfrying fats in relation to fat mutagen content. Food Chem Toxicol 29, 689-698.

48. Arbillaga L, Azqueta A, van Delft JH, et al. (2007) In vitro gene expression data supporting a DNA non-reactive genotoxic mechanism for ochratoxin A. Toxicol Appl Pharmacol 15, 216-224.

49. Kimihiko S \& Ichiro H (2002) Anomalous elevation of glutathione$S$-transferase P-form (GST-P) in the elementary process of epigenetic initiation of chemical hepatocarcinogenesis in rats. Carcinogenesis 23, 1193-1198. 